\title{
ALTERAÇÕES HEPÁTICAS EM DECORRÊNCIA DA INFECÇÃO PELO VÍRUS DA DENGUE
}

\section{ARTIGO DE REVISÃO}

SOUSA, Daniel Francisco de ${ }^{1}$, MOURA, Amarildo Lemos Dias de ${ }^{2}$, CASTRO, Fernanda de Oliveira Feitosa de ${ }^{3}$, PFRIMER, Irmtraut Araci Hoffmann ${ }^{4}$

SOUSA, Daniel Francisco de. Et al. Alterações hepáticas em decorrência da infecção pelo vírus da Dengue. Revista Científica Multidisciplinar Núcleo do Conhecimento. Ano. 06, Ed. 12, Vol. 02, pp. 92-106. Dezembro de 2021. ISSN: 2448-0959, Link de acesso:

https://www.nucleodoconhecimento.com.br/saude/alteracoes-hepaticas, DOI: 10.32749/nucleodoconhecimento.com.br/saude/alteracoes-hepaticas

\section{RESUMO}

É comum as alterações hepáticas na infecção pela dengue. As lesões nos hepatócitos são refletidas no aumento de transaminases que servem como biomarcadores de gravidade da doença. Diversas outras alterações clínicas e laboratoriais acompanham a evolução da dengue podendo ser observadas nos resultados laboratoriais. Diante disto, o presente artigo, tem questão norteadora: quais alterações clínicas e laboratoriais podem se correlacionar com o aumento das transaminases hepáticas produzidas na infecção pela dengue? Objetivos: Avaliar e correlacionar as alterações clínicas e laboratoriais observadas nos pacientes infectados pela dengue, principalmente nas mudanças hepáticas. Metodologia: Revisão de artigos atualizados sobre as alterações hepáticas na infecção pela

\footnotetext{
${ }^{1}$ Graduando Em Ciências Biológicas Modalidade Médica. ORCID: 0000-0002-0125-944X.

2 Mestrado Em Ciências Biológicas; Especialização Em Docência Universitária; Graduação Em Ciências Biológicas - Modalidade Médica. ORCID: 0000-0002-1029-145X.

${ }^{3}$ Doutorado Em Medicina Tropical E Saúde Pública - Área De Concentração: Imunologia - Mestrado Em Ciências Ambientais E Saúde - Graduação Em Ciências Biológicas - Modalidade Médica. ORCID: 0000-00015832-7821.

${ }^{4}$ Orientadora. ORCID: 0000-0002-3737-0027.
}

RC: 102781

Disponível em: https://www.nucleodoconhecimento.com.br/saude/alteracoeshepaticas 
dengue. Foram incluídos artigos que não utilizassem estudos com uma coorte apenas de crianças, testes em animais, ou voluntários com doenças hepáticas preexistentes a infecção. Foram selecionados artigos do período de 2016 a 2021, com resumo e no idioma inglês ou português. Foram encontrados 1.516 artigos. Após a utilização dos descritores na busca, esse número resultou em 728 artigos. Após a leitura dos títulos, foram excluídos 700 artigos do estudo. Dos 28 artigos remanescentes, foram todos lidos na íntegra, sendo que 18 foram excluídos, resultando em 10 artigos selecionados. Resultados: Trombocitopenia nem sempre se correlaciona com a hemorragia comumente relatada na dengue grave. Outros exames podem ser utilizados também como preditores da doença como: ferritina, contagem de leucócitos e outras enzimas sorológicas. AST e ALT podem ser utilizados como marcadores de evolução da gravidade da dengue e de lesões nos hepatócitos.

Palavras-chave: Dengue, Alterações Hepáticas, AST, ALT.

\section{INTRODUÇÃO}

O vírus da dengue é um arbovírus que pertence à família Flaviviridae e ao gênero Flavivirus. Os principais vetores do vírus da dengue são os mosquitos Aedes aegypti e $A$. albopictus encontrados em regiões de clima tropical e subtropical. $\mathrm{O}$ vírus apresenta RNA de fita simples ( 10,7 kb), polaridade positiva e possui quatro sorotipos: DENV1, DENV2, DENV3 e DENV4, todos com capacidade de levar o indivíduo a óbito principalmente se ocorrer uma reinfecção por um sorotipo diferente. Seu genoma codifica 3 proteínas estruturais (C, prM / M, E) e 7 não estruturais (NS1, NS2A, NS2B, NS3, NS4A, NS4B e NS5) (WARDHANI et al., 2017).

Essa doença já fez mais de 13 milhões de vítimas só no Brasil, de 1970 a 2017 de acordo com Salles et al. (2018). Os casos de dengue aumentaram 30 vezes nas últimas décadas e ocorrem em mais 128 países. Aproximadamente 25 mil pessoas morrem pela forma grave da dengue anualmente, e mais de 390 milhões são infectadas em todo o mundo Xu et al. (2018); Wang et al. (2020), gerando um custo 
aos cofres públicos de mais de 1 bilhão de dólares ano (TEERASARNTIPAN et al., 2020). Além disso, é uma doença endêmica que não possui vacina eficaz ainda e seu tratamento é relacionado aos sinais e sintomas (SALLES et al., 2018).

As manifestações clínicas da dengue podem variar de forma assintomática a fatal. Conforme o Ministério da Saúde (2016), os casos de dengue são classificados em Dengue (D), Dengue com Sinais de Alarme (DSA) e Dengue Grave (DG). A Dengue é uma doença leve que se caracteriza com sintomas como febre, erupção cutânea, mialgia, dores nas articulações e cefaleia. Ela pode causar também a Dengue com Sinais de Alarme, que é uma doença grave caracterizada por vazamento de plasma, dispneia e hemorragia grave ou insuficiência de órgãos, sendo potencialmente letal; isso em conjunto com os sintomas da $D$ mais sangramento da mucosa bucal, vômito constante e com sangue e dores fortes no abdômen. A DSA, ainda pode evoluir para a DG, onde há hemorragia severa para o espaço pleural e cavidade peritoneal por exemplo (TEERASARNTIPAN et al., 2020).

Em alguns casos essas infecções vêm acompanhadas de um quadro de insuficiência hepática. Os mecanismos que desencadeiam essas alterações hepáticas são lesões virais causadas diretamente aos hepatócitos; resposta imune desregulada devido à infecção viral como o aumento de radicais livres e hipoxia devido ao vazamento capilar tornando a irrigação no órgão escassa, o que pode resultar no aumento das transaminases séricas (TEERASARNTIPAN et al., 2020).

A OMS relata que as alterações clínicas causadas principalmente na forma grave da dengue são: diminuição de células brancas, plaquetas, fibrinogênio, protrombina, fator VIII, fator XII e antitrombina III, albuminemia, aumento de enzimas hepáticas como AST (aspartato aminotransferase), ALT (alanina aminotransferase) e outros cofatores hepáticos (OMS, 2011). Ainda de acordo com a OMS, os resultados do estudo de Shivkar (2018) mostraram que os 40 pacientes que tiveram trombocitopenia apresentaram níveis de transaminases consideravelmente mais elevados. A queda do número de plaquetas está relacionada com a gravidade da doença, pelas diretrizes da OMS (2011). 
O fígado produz as enzimas AST e ALT que são consideradas marcadores de lesão hepática. Essas transaminases aumentam significativamente na infecção aguda da dengue e podem ser usadas como predição de gravidade da doença em casos agudos (RAO et al., 2020).

Diante desse contexto, quais alterações clínicas e laboratoriais podem se correlacionar com o aumento das transaminases hepáticas produzidas na infecção pela dengue? Assim, o objetivo desse estudo foi avaliar as alterações das transaminases na infecção pelo DENV, realizando uma revisão da literatura, correlacionando os resultados encontrados nos estudos com as alterações fisiológicas e laboratoriais de pacientes infectados por DENV.

\section{METODOLOGIA}

Trata-se de uma revisão sistemática da literatura e a seleção de artigos científicos que constituirão esta revisão seguirá as orientações do PRISMA (Preferred Reporting Items for Systematic Reviews and Meta-Analyses) (MOHER, 2015).

Foi realizada uma revisão da literatura dos artigos publicados no Portal de Periódicos CAPES (Coordenação de Aperfeiçoamento de Pessoal de Nível Superior), nas bases de dados eletrônicos - PubMed Central, SciELO, Science Citation Index Expanded - Web of Science e Scopus - Elsevier, entre o período de 2016 até 2021. Como critérios de inclusão os estudos deveriam ser somente artigos, serem revisados aos pares e escritos em inglês ou português.

As buscas foram conduzidas através de descritores listados no Descritor em Ciências da Saúde - DeCs e no Medical Subject Headings - MeSH, dos quais podemos citar: DENGUE; AST AND ALT; TRANSAMINASES além de utilizar os operadores booleanos "AND" e "OR". Para conduzir a busca os descritores deveriam estar contidos no título e/ou resumo dos trabalhos.

Em seguida foram excluídos os artigos que não estavam relacionados ao tema e procedeu-se a leitura dos resumos. Somente foram incluídos os artigos que

RC: 102781

Disponível em: https://www.nucleodoconhecimento.com.br/saude/alteracoeshepaticas 
avaliaram as alterações das transaminases de indivíduos infectados por dengue. Foram excluídos artigos de revisão, artigos que analisavam a infecção em crianças e estudos que não possuíam resumo. Na etapa seguinte foi feita a leitura na íntegra dos artigos selecionados e conduzida a extração dos dados.

Ao todo foram identificados 1.516 artigos, sendo inicialmente excluídos 788 artigos cujo idiomas eram diferentes do inglês ou português e/ou pelo critério da análise da seleção por período e palavras-chaves. Entre os 728 artigos remanescentes da identificação, a priori, 700 artigos não corresponderam à triagem após a leitura do título. Destes 28 pré-selecionados de acordo com os critérios de elegibilidade, 18 artigos foram excluídos por serem revisão sistemática ou não estarem associados às alterações nas transaminases em indivíduos infectados por dengue. Ao final, 10 artigos foram incluídos na pesquisa e que seguem todos os critérios mencionados de identificação, triagem e elegibilidade. O fluxograma de seleção dos estudos está apresentado na figura 1 .

\section{RESULTADOS}

Os artigos encontrados fornecem informações importantes que ajudam no prognóstico da dengue. Encontramos artigos que comparavam diferentes grupos de pacientes, nos quais manifestavam diferenças clínicas e laboratoriais decorrentes da doença, e seus níveis séricos de enzimas hepáticas. Geralmente, os grupos com sinais de alerta mais presentes, tenderam a ter um aumento maior de transaminases. Outros artigos incluídos na revisão, concluíram não haver discrepâncias expressivas em AST/ALT quando comparavam grupos infectados por dengue, não obstante, esses mesmos estudos apresentaram possíveis interferências e limitações no trabalho. Foram incluídos artigos que relataram outras possíveis causas da hemorragia na infecção por dengue. 
Figura 1: Esquema da seleção dos artigos para a revisão.

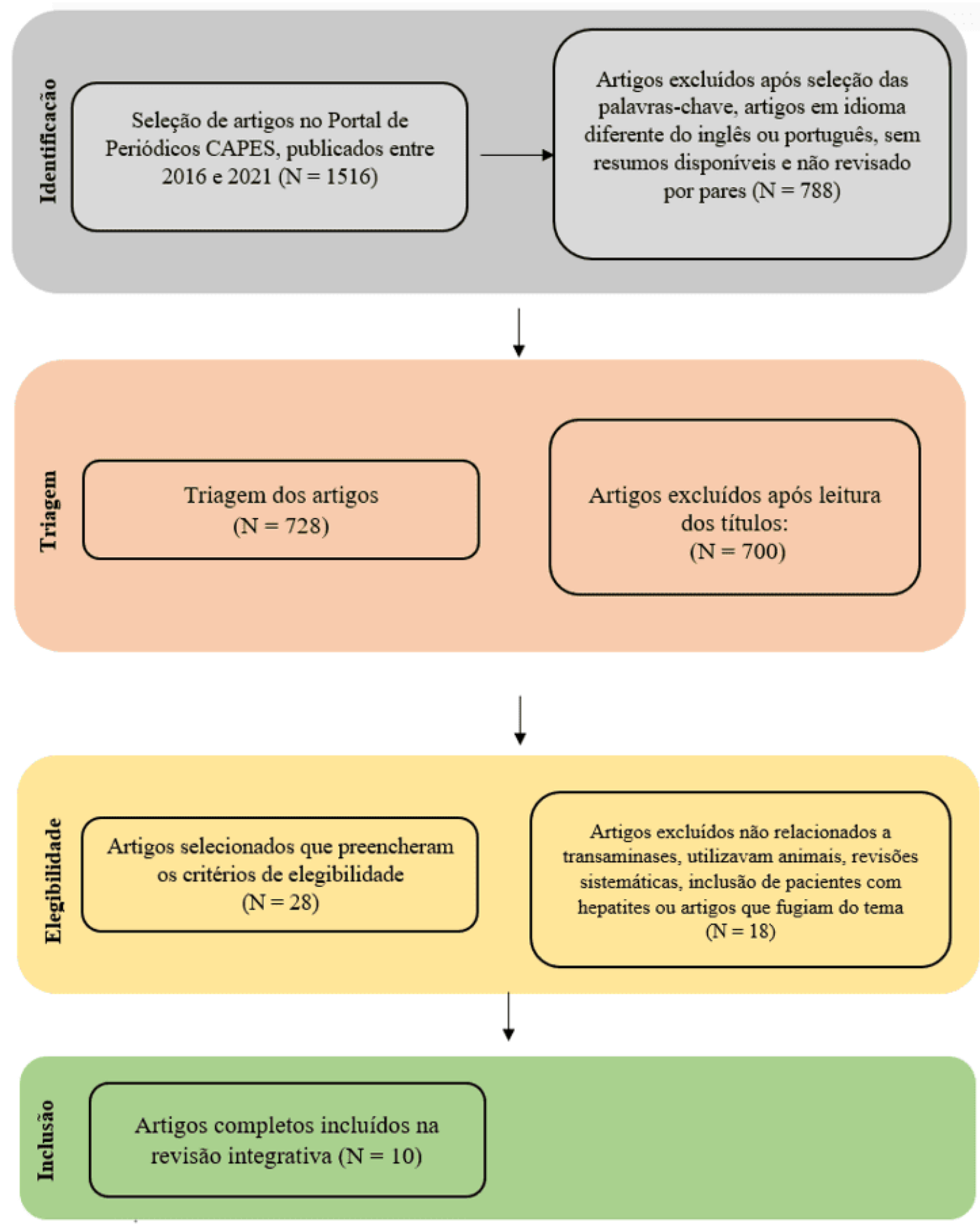

Fonte: Autoria própria (2021).

RC: 102781

Disponível em: https://www.nucleodoconhecimento.com.br/saude/alteracoeshepaticas 
Tabela 1: Resumo dos dados dos artigos selecionados e as respectivas alterações nas transaminases.

\begin{tabular}{|c|c|c|c|c|}
\hline AUTORES/ANO & $\mathrm{N}$ & AST & ALT & CONCLUSÃO \\
\hline $\begin{array}{l}\text { WARDHANI et } \\
\text { al., } 2017\end{array}$ & $\begin{array}{l}19 \text { (adultos) } \\
\text { confirmados } \\
\text { com } \\
\text { dengue. } \\
D \quad(\mathrm{~N}=9) \text {, } \\
\mathrm{DSA} \\
(\mathrm{N}=10)\end{array}$ & $\begin{array}{l}\text { Adultos: D } \\
(101,0+/-34,3) ; \\
\text { DSA } \\
(139,8+/-81,9) .\end{array}$ & $\begin{array}{l}\text { Adultos: D } \\
(87,1+/- \\
39,7) ; \quad \text { DSA } \\
(75,8+/- \\
60,8) .\end{array}$ & $\begin{array}{l}\text { Foram } \\
\text { observados } \\
\text { níveis mais altos } \\
\text { de AST e ALT } \\
\text { nos pacientes } \\
\text { com Dengue } \\
\text { hemorrágica. } \\
\text { Entre crianças e } \\
\text { pacientes } \\
\text { adultos, } \\
\text { manifestações e } \\
\text { os sintomas da } \\
\text { dengue } \\
\text { Surabaya foram } \\
\text { mais } \\
\text { proeminentes } \\
\text { nas crianças. } \\
\text { Outros } \\
\text { parâmetros } \\
\text { clínicos/laborator } \\
\text { iais não foram } \\
\text { significativament } \\
\text { e diferentes em } \\
\text { pacientes } \\
\text { adultos entre D e } \\
\text { DSA. }\end{array}$ \\
\hline PADYANA et & 96 & Sobreviventes & Sobrevivent & O envolvimento \\
\hline
\end{tabular}


REVISTA CIENTÍFICA MULTIDISCIPLINAR NÚCLEO DO CONHECIMENTO ISSN: 2448-0959

https://www.nucleodoconhecimento.com.br

\begin{tabular}{|c|c|c|c|c|}
\hline 2019 & $\begin{array}{l}\text { pacientes } \\
\text { confirmados } \\
\text {. }\end{array}$ & $\begin{array}{l}299,5 \quad(148- \\
1098,5) . \\
\text { Não } \\
\text { sobreviventes } \\
4936(2431,5 \text { - } \\
14340,3) .\end{array}$ & $\begin{array}{l}\text { es } 163 \\
(83,75- \\
469,5) . \\
\text { Não } \\
\text { sobrevivent } \\
\text { es } \quad 1412 \\
(613- \\
3832,75) .\end{array}$ & $\begin{array}{lr}\text { de órgãos } & \text { e } \\
\text { score para } & \text { pa } \\
\text { deteç̧ão de } \\
\text { severidade da } \\
\text { doença são } \\
\text { fortes preditores } \\
\text { de mortalidade } \\
\text { na infecção por } \\
\text { DENV. }\end{array}$ \\
\hline
\end{tabular}

\begin{tabular}{|c|c|c|c|c|}
\hline $\begin{array}{l}\text { RAO et al., } \\
2020\end{array}$ & $\begin{array}{l}106 \\
\text { pacientes } \\
\text { confirmados }\end{array}$ & $\begin{array}{l}\text { AST presente } \\
\text { em } 85 \% \text { dos } \\
\text { pacientes } \\
\text { (ROC curve) } \\
\text { Níveis : 1737 } \\
\text { U/L cut-off } 134 \\
\text { u/L. }\end{array}$ & $\begin{array}{l}\text { ALT } \\
\text { presente } \\
\text { em } 84 \% \\
\text { dos } \\
\text { pacientes } \\
\text { Níveis: } 502 \\
\text { u/L cut-off: } \\
88 \text { u/L. }\end{array}$ & $\begin{array}{l}\text { As } \\
\text { transaminases } \\
\text { aumentaram } \\
\text { consideravelmen } \\
\text { te, afirmando } \\
\text { que esses } \\
\text { parâmetros } \\
\text { podem ser } \\
\text { usados como } \\
\text { marcadores para } \\
\text { predição de } \\
\text { Dengue em } \\
\text { casos agudos. } \\
\text { Ferritina, AST e } \\
\text { ALT, podem ser } \\
\text { os melhores } \\
\text { preditores para } \\
\text { avaliar a doença } \\
\text { e sua gravidade. }\end{array}$ \\
\hline $\begin{array}{l}\text { XU et al., } \\
2018\end{array}$ & $\begin{array}{l}3804 \\
\text { pacientes }\end{array}$ & $\begin{array}{l}\text { AST: } \\
\text { (Chineses: }\end{array}$ & $\begin{array}{l}\text { ALT: } \\
\text { (Chineses: }\end{array}$ & $\begin{array}{l}\text { No estudo foi } \\
\text { definido que o }\end{array}$ \\
\hline
\end{tabular}

RC: 102781

Disponível em: https://www.nucleodoconhecimento.com.br/saude/alteracoeshepaticas 
REVISTA CIENTÍFICA MULTIDISCIPLINAR NÚCLEO DO CONHECIMENTO ISSN: 2448-0959

https://www.nucleodoconhecimento.com.br

\begin{tabular}{|c|c|c|c|c|}
\hline & $\begin{array}{l}(2.609 \\
\text { chineses / } \\
1195 \\
\text { migrantes). }\end{array}$ & $\begin{array}{l}\text { 130U/L). } \\
\text { (Migrantes:87U } \\
\text { /L); }\end{array}$ & $\begin{array}{l}\text { 82U/L) } \\
\text { (Migrantes: } \\
52 \\
\mathrm{U} / \mathrm{L} \text { ) }\end{array}$ & 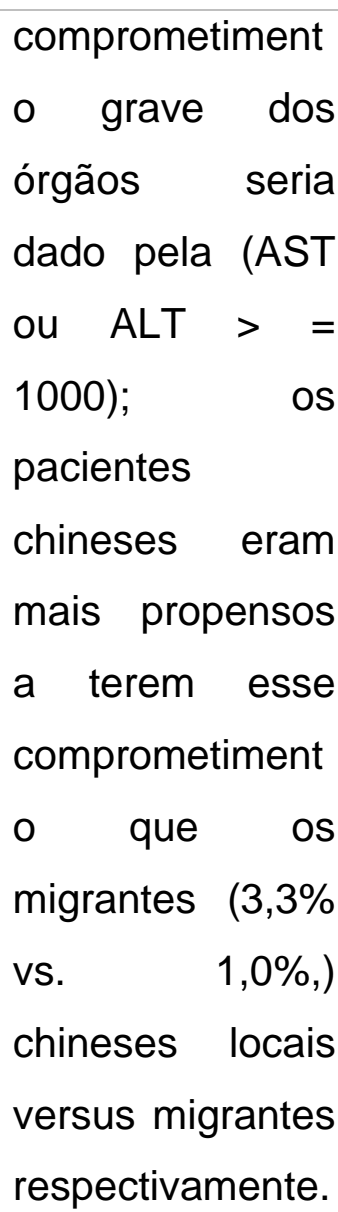 \\
\hline $\begin{array}{l}\text { WANG et al., } \\
2020\end{array}$ & $\begin{array}{l}718 \\
\text { pacientes. }\end{array}$ & $\begin{array}{l}\text { AST } \quad(40-80 \\
\text { U/L, } \quad \mathrm{N}=261) ; \\
(80-200 U / L, \\
N=179) ; \\
(200-400 U / L, \\
N=35) ; \\
(>400 U / L, \\
N=13) .\end{array}$ & $\begin{array}{l}\text { ALT } \quad(40-80 \\
\text { U/L, } \quad N= \\
257) ; \\
(80-200 U / L, \\
N=168) ; \\
(200- \\
400 U / L, \\
N=26) ; \\
(>400 U / L, \\
N=9) .\end{array}$ & $\begin{array}{l}\text { A leucopenia foi } \\
\text { a complicação } \\
\text { com maior taxa } \\
\text { de incidência } \\
\text { ( } 504 \text { casos); } \\
\text { Trombocitopenia } \\
\text { (380 casos): } \\
\text { aumento de AST } \\
\text { (488 casos), ALT } \\
\text { (460 casos); a } \\
\text { concentração } \\
\text { média de AST foi } \\
\text { maior que ALT e }\end{array}$ \\
\hline
\end{tabular}

RC: 102781

Disponível em: https://www.nucleodoconhecimento.com.br/saude/alteracoeshepaticas 


\begin{tabular}{|c|c|c|c|c|}
\hline & & & & $\begin{array}{l}\text { tem uma razão. } \\
\text { AST } \\
\text { proveniente } \\
\text { também de } \\
\text { isoenzimas } \\
\text { produzidas pela } \\
\text { lesão celular no } \\
\text { miocárdio, além } \\
\text { de ser produzida } \\
\text { no fígado } \\
\text { também. Como } \\
\text { os pacientes } \\
\text { possuíam lesão } \\
\text { cardíaca de } \\
\text { acordo com as } \\
\text { enzimas } \\
\text { marcadoras, } \\
\text { esse aumento de } \\
\text { AST foi em } \\
\text { decorrência } \\
\text { deste fato. }\end{array}$ \\
\hline $\begin{array}{l}\text { WONG et al., } \\
2016\end{array}$ & $\begin{array}{l}4383 \\
\text { adultos } \\
\text { hospitalizad } \\
\text { os: } 188 \\
\text { (confirmado } \\
\text { s com } \\
\text { Dengue e } \\
\text { CSB); } 4195 \\
\text { (confirmado }\end{array}$ & $\begin{array}{l}\text { AST, para } \\
\text { pacientes com } \\
\text { CSB a média } \\
\text { foi de 113U/L } \\
\text { (37-785); } \\
\text { SEM } \\
\text { CSB=113U/L } \\
(35-502) .\end{array}$ & $\begin{array}{l}\text { ALT, com } \\
\text { CSB = } 66 \\
(20-591) ; \\
\text { SEM-CSB= } \\
69 U / L \\
(20-350) ;\end{array}$ & $\begin{array}{l}\text { AST, } \\
\text { possivelmente } \\
\text { nesse estudo, foi } \\
\text { um fator de risco } \\
\text { de CSB } \\
\text { (Sangramento } \\
\text { Clinicamente } \\
\text { Significativo) em } \\
\text { pacientes }\end{array}$ \\
\hline
\end{tabular}

RC: 102781

Disponível em: https://www.nucleodoconhecimento.com.br/saude/alteracoeshepaticas 


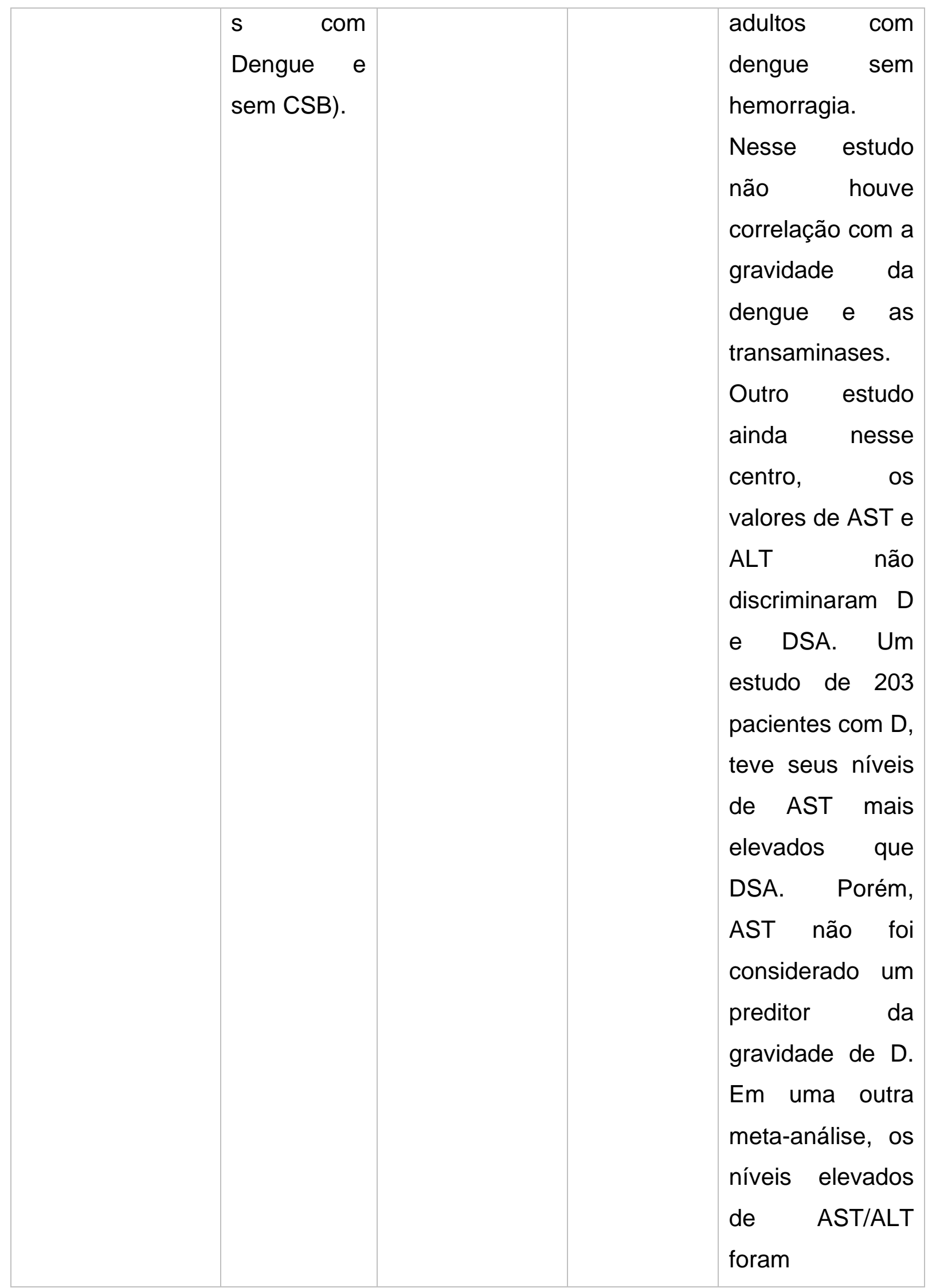

RC: 102781

Disponível em: https://www.nucleodoconhecimento.com.br/saude/alteracoeshepaticas 
DG.

\begin{tabular}{|c|c|c|c|c|}
\hline $\begin{array}{l}\text { KHAN et al., } \\
2020\end{array}$ & $\begin{array}{l}168 \\
\text { pacientes } \\
\text { confirmados }\end{array}$ & $\begin{array}{l}\text { DENV-1: } \\
228 \quad(59-406) ; \\
\text { DENV-2: } \\
139 \quad(27-570) ; \\
\text { DENV-3: } \\
114 \quad(41-288) ; \\
\text { DENV-4: (ND) }\end{array}$ & $\begin{array}{l}\text { DENV-1: } \\
101 \quad(20- \\
247) ; \\
\text { DENV-2: } \\
146 \quad(16- \\
751) ; \\
\text { DENV-3: } \\
83.3 \quad(28- \\
277) ; \\
\text { DENV-4: } \\
86.2 \quad(28- \\
221) .\end{array}$ & $\begin{array}{l}\text { Na infecção por } \\
\text { DENV-1 foi visto } \\
\text { que existe } 2 \\
\text { vezes maior } \\
\text { probabilidade de } \\
\text { ter AST elevada } \\
\text { e 1,86 vezes } \\
\text { mais de ALT } \\
\text { elevada quando } \\
\text { comparado com } \\
\text { os outros três } \\
\text { subtipos virais. } \\
\text { DENV-1 } \\
\text { apresentou } \\
\text { maior impacto no } \\
\text { fígado com maior } \\
\text { frequência de } \\
\text { alterações } \\
\text { anormais nos } \\
\text { testes de função } \\
\text { hepática. }\end{array}$ \\
\hline NG et al., 2016 & $\begin{array}{l}2842 \\
\text { confirmados } \\
\text { com } \\
\text { Dengue } \\
\text { sendo que, } \\
532 \text { com } \\
\text { febre }\end{array}$ & 135 (34-943) & $76(18-595)$ & $\begin{array}{l}\text { Níveis } \\
\text { aumentados de } \\
\text { AST e ALT foram } \\
\text { associados com } \\
\text { a febre } \\
\text { prolongada na } \\
\text { infecção por }\end{array}$ \\
\hline
\end{tabular}

RC: 102781

Disponível em: https://www.nucleodoconhecimento.com.br/saude/alteracoeshepaticas 


\begin{tabular}{|c|c|c|c|c|}
\hline & $\begin{array}{l}\text { prolongada } \\
\text { (>14 dias). }\end{array}$ & & & $\begin{array}{l}\text { DENV, sendo um } \\
\text { dos sinais de } \\
\text { alarme para as } \\
\text { formas mais } \\
\text { graves da } \\
\text { dengue. }\end{array}$ \\
\hline KAM et al., 2020 & $\begin{array}{l}170 \\
\text { pacientes } \\
\text { confirmados } \\
\text {. }\end{array}$ & $64(+/-20,1)$ & $\begin{array}{l}75,2 \quad(+/- \\
21,2) \quad\end{array}$ & $\begin{array}{l}\text { Observações } \\
\text { clínicas e os } \\
\text { parâmetros } \\
\text { laboratoriais, } \\
\text { assim como a } \\
\text { detecção de } \\
\text { mediadores } \\
\text { imunes } \\
\text { específicos } \\
\text { podem auxiliar } \\
\text { no diagnóstico } \\
\text { diferencial de } \\
\text { arboviroses de } \\
\text { pacientes febris. }\end{array}$ \\
\hline $\begin{array}{l}\text { TEERASARNTIP } \\
\text { AN et al., } 2020\end{array}$ & $\begin{array}{l}\text { DISH } \\
(\mathrm{N}=151) ; \\
\text { DISH SEM } \\
\text { ALF } \\
(\mathrm{N}=134) ; \\
\text { DISH COM } \\
\text { ALF }(N=17) .\end{array}$ & $\begin{array}{l}\text { DISH } \\
(1547+/- \\
2254.3) ; \\
\text { DISH SEM ALF } \\
(1130+/- \\
1302.5) ; \quad \text { DISH } \\
\text { COM ALF } \\
\text { (4804.3+/4540. } \\
4) .\end{array}$ & $\begin{array}{l}\text { DISH } \\
(694.3+/- \\
725.1) ; \\
\text { DISH SEM } \\
\text { ALF } \\
(590.8+/- \\
493.6) ; \\
\text { DISH COM } \\
\text { ALF } \\
(1510.5+/-\end{array}$ & $\begin{array}{lr}\text { Pacientes } & \text { que } \\
\text { tiveram DISH } \\
\text { (Hepatite } & \text { Severa } \\
\text { Induzida por } \\
\text { Dengue) com } \\
\text { ALF } \\
\text { (Insuficiência } \\
\text { Hepática } \\
\text { tiveram suda), } \\
\text { resultados de }\end{array}$ \\
\hline
\end{tabular}

RC: 102781

Disponível em: https://www.nucleodoconhecimento.com.br/saude/alteracoeshepaticas 


\begin{tabular}{|l|l|l|}
\hline 1451.6). & $\begin{array}{l}\text { AST e ALT, e } \\
\text { outros exames } \\
\text { laboratoriais, } \\
\text { mais elevados } \\
\text { que os pacientes } \\
\text { de DISH sem } \\
\text { ALF. }\end{array}$ \\
\hline
\end{tabular}

Fonte: Autoria própria (2021).

\section{DISCUSSÃO}

O estudo em questão avaliou os dados da literatura com resultados das alterações nas transaminases hepáticas na infecção por dengue.

Discute-se muito sobre encontrar preditores cada vez mais precisos na evolução da doença da dengue. Um dos maiores problemas atualmente no quadro clínico do paciente infectado, é sua piora na doença resultando em perda sanguínea que pode levar o indivíduo a óbito. Os estudos de Padyana et al. (2019) apontam que os indivíduos mais jovens tendem a ter uma clínica mais grave que pacientes mais velhos. Essa informação corrobora com os resultados de Wardhani et al. (2017) que mostram os marcadores de gravidade mais frequentes em crianças do que em adultos. Alguns estudos observaram que as transaminases podem ser aliadas no prognóstico de uma hemorragia na infecção por dengue (RAO et al., 2020).

Sabe-se que AST e ALT são biomarcadores que indicam lesão nos hepatócitos. O aumento dessas enzimas em uma infecção pela dengue, se deve à replicação do vírus nas células do fígado, à resposta imune desregulada e a hipóxia devido a perda de plasma. Essa desregulação pode indicar início de uma evolução da gravidade, podendo levar o indivíduo ao óbito. No trabalho realizado pela Padyana et al. (2019), foram avaliadas as diferenças clínicas e laboratoriais dos pacientes sobreviventes e não-sobreviventes após infecção pela dengue. Os níveis de AST 
apresentaram aumento de 10 vezes nos pacientes que não sobreviveram em relação aos que sobreviveram. Assim como, os níveis de ALT apresentaram aumento também significativo para esse mesmo grupo, que não sobreviveram, mostrando que as alterações nos níveis plasmáticos dessas enzimas servem como marcadores de gravidade da doença.

É comum observar quadros de alterações hepáticas em indivíduos infectados por dengue. Essas alterações se refletem no aumento das transaminases séricas, o que pode servir como prognóstico para uma evolução de uma insuficiência hepática aguda. Os estudos de Teerasarntipan et al. (2020), relataram que uma hepatite grave causada pela dengue, pode aumentar em até 10 vezes os níveis de transaminases. Porém, quando essa hepatite evolui para uma insuficiência hepática aguda, o quadro do paciente se torna muito mais grave. Nesse estudo, 151 dos pacientes obtiveram a hepatite grave. Destes pacientes, 17 evoluíram para uma insuficiência hepática aguda, e tiveram as médias dos resultados de AST e ALT muito mais elevados do que os que não evoluíram (TEERASARNTIPAN et al., 2020). Nesse contexto, as mesmas transaminases também aumentaram, no estudo de $\mathrm{Ng}$ et al. (2016), em 532 pacientes infectados por dengue que foram diagnosticados com uma prolongação da dengue. Isso significa que AST e ALT, como marcadores bastante sensíveis, podem sim ser usados como parâmetros de avaliação do fígado na infecção aguda da dengue e, também como preditor do avanço da febre.

A hemorragia pode ser um fator preponderante na explicação de muitas alterações dos exames laboratoriais dos pacientes infectados e hemorrágicos. Nos estudos de Lee et al. (2016), em $80 \%$ de todos os seus pacientes, os casos de sangramento gastrointestinal foram observados após o 4ํㅜ dia de início da doença. Zhao et al. (2016) apresentaram nos seus resultados que o grupo de pacientes com dengue leve, não desenvolveu hemorragia e teve seus valores de AST/ALT menores que o grupo de pacientes que evoluíram para hemorragia. Esse mesmo estudo (ZHAO et al., 2016) afirmou que um dos fatores principais na causa da hemorragia da infecção pelo vírus é a resposta imune desordenada, gerando uma produção excessiva de 
citocinas que piora o quadro do paciente. O TNF- $\alpha$ foi a citocina mais proeminente nos casos de dengue grave, o mesmo grupo onde houve aumento das transaminases. É sabido que o aumento dessa citocina pode causar problemas sistêmicos importantes, como diversas lesões vasculares, gerando um quadro intenso de hipóxia em órgãos vitais, como no fígado, coração e rins.

O trabalho de Wong et al. (2016) mostrou que não houve relação da variação dos níveis séricos de transaminases com a distinção de D e DSA. Porém, explicou que seu estudo teve limitações por incluir uma série de grupos étnicos diferentes do Sudeste Asiático e utilizarem valores laboratoriais apenas do dia da admissão do paciente, sem uma padronização do período de coleta da amostra. Isso pode gerar resultados nem sempre confiáveis dos testes. Vários fatores podem ser considerados interferentes no resultado de exames laboratoriais. Xu et al. (2018), mostrou que os Chineses tiveram níveis de AST e ALT muito maiores que os migrantes chineses. Ao comparar a tabela desses dois grupos é visto que comorbidades como hipertensão e Diabetes Mellitus eram mais frequentes no primeiro grupo que no outro. Essas doenças podem interferir nos resultados, uma vez que são doenças sistêmicas que podem acometer todo o organismo do indivíduo.

É normal pensar que uma hemorragia grave, necessariamente é resultado de uma plaquetopenia no paciente infectado pela dengue. Dhanoa et al. (2016) apresentaram que em sua coorte estudada a grande maioria testou positivo para DENV-2, logo, os casos de alterações laboratoriais como queda no número de plaquetas se apresentaram maior na infecção para este sorotipo viral. A frequência de trombocitopenia grave $\left(<50.000 / \mathrm{mm}^{3}\right)$ não teve necessariamente uma correlação com a queda de plaquetas e com a hemorragia, mas sim, com outras doenças como a lesão no fígado, vasculopatias, deficiência na coagulação e sistema fibrinolítico e, também na produção exagerada de citocinas pró-inflamatórias. Corroborando com o estudo de Rao et al. (2020), que informaram que a máxima de queda plaquetária de um paciente internado não mostrou qualquer significância como indicador de gravidade.

RC: 102781

Disponível em: https://www.nucleodoconhecimento.com.br/saude/alteracoeshepaticas 
Em relação aos sorotipos do DENV, é difícil associá-los à gravidade e alterações clínicas e laboratoriais do infectado. Wardhani et al. (2017) mostraram que as únicas alterações significativas observadas entre os sorotipos virais foram a contagem de linfócitos e uma carga viral mais elevada em DENV-1, mas que as características clínicas e laboratoriais dos pacientes não tiveram discrepâncias expressivas entre os subtipos virais. O estudo de Khan et al. (2020), mostra que o sorotipo 1 da dengue, tem duas vezes mais chances de ter os níveis das transaminases elevadas que em outros sorotipos. Os relatos corroboram com o estudo de Rao et al. (2020), que enfatiza o fato que sua coorte estudada teve predominância do DENV-3, porém, conclui que não houve associação entre os sorotipos da dengue e a gravidade da doença. Isso mostra que a infecção por qualquer um dos quatro tipos deste vírus pode ser grave ou não, sendo que o diagnóstico de subtipo viral não é preditivo de gravidade.

Sabe-se que a reinfecção por um sorotipo diferente da dengue pode ser a causa de gravidade desta doença. Isso acontece porque os linfócitos ativados no primeiro contágio não terão afinidade pelo novo sorotipo viral. Assim, poderá ocorrer uma resposta imune desregulada com a produção de uma "tempestade de citocinas", contribuindo com a gravidade da doença. Quando os pacientes têm uma coinfecção (infecção por dois sorotipos diferentes em fase aguda), a resposta imune que irá se desenvolver será feita como uma única inoculação, ou seja, será como uma resposta a um único sorotipo (KHAN et al., 2020). A doença da dengue tem os sintomas semelhantes a outras enfermidades que comumente são vistos em cocirculação, como Chikungunya e Zika. Utilizando-se somente a avaliação clínica do paciente pode ocorrer um diagnóstico errado. Por isso, são necessários os testes sorológicos e moleculares para diferenciação de outras doenças além da dengue (KAM et al., 2020).

A forma grave da dengue pode atingir o sistema nervoso, levando a quadro de meningite no indivíduo infectado. O estudo de Wang et al. (2021), apresentou que três pacientes desenvolveram sintomas neurológicos, em menos de 10 dias após o início da doença. A diminuição de leucócitos pode favorecer a expansão do vírus RC: 102781

Disponível em: https://www.nucleodoconhecimento.com.br/saude/alteracoes$\underline{\text { hepaticas }}$ 
para tecidos importantes, como o tecido nervoso. Nesse estudo, 504 pacientes apresentaram leucopenia, que foi a alteração com maior prevalência entre os indivíduos. Esse resultado sugere que a baixa produção de células brancas pode ser devido a diminuição da irrigação sanguínea nos tecidos hematopoiéticos, uma vez que $75 \%(N=380)$ dos pacientes com leucopenia, tiveram quadros hemorrágicos.

\section{CONSIDERAÇÕES FINAIS}

Retomando à questão norteadora: quais alterações clínicas e laboratoriais podem se correlacionar com o aumento das transaminases hepáticas produzidas na infecção pela dengue? Foi observado que o aumento dos níveis das transaminases está diretamente relacionado com as alterações clínicas e laboratoriais em pacientes infectados pela dengue. Conforme foi observado nos artigos selecionados, as alterações de AST e ALT estão presentes na infecção pela dengue e que seus aumentos no soro do paciente são proporcionais à evolução da doença. Foi observado ainda que a diminuição na contagem de plaquetas não é um bom marcador para hemorragia pela dengue e que o sorotipo viral não é um bom indicador de gravidade da infecção.

\section{REFERÊNCIAS}

DHANOA, Amreeta et al. Impact of dengue virus (DENV) co-infection on clinical manifestations, disease severity and laboratory parameters. BMC Infect Dis, [s. I.], v. 16, n. 1, p. 406-420, 11 Aug. 2016.

KAM, Yiu-Wing et al. Systematic analysis of disease-specific immunological signatures in patients with febrile illness from Saudi Arabia. Clin TransI Immunology, [s. I.], v. 0, n. 8, p. e1163, 22 Aug. 2020.

KHAN, Erum et al. The Clinical Features of Co-circulating Dengue Viruses and the Absence of Dengue Hemorrhagic Fever in Pakistan. Front Public Health, [s. I.], v. 8, p. 287-299, 17 June. 2017. 
LEE, Ing-Kit et al. Development of a Simple Clinical Risk Score for Early Prediction of Severe Dengue in Adult Patients. PLoS One, [s. I.], v. 11, n. 5, p. e0154772, 3 May. 2016.

MOHER, David et al. Preferred Reporting Items for Systematic Reviews and MetaAnalyses: The PRISMA Statement. PLoS Med, [s. I.], v. 6, n. 7, p. e1000097, 21 July. 2009.

MOHER, David et al. Preferred reporting items for systematic review and metaanalysis protocols (PRISMA-P) 2015 statement. Systematic Reviews, [s. I.], v. 4, n. 1, 1 Jan. 2015.

MS - MINISTÉRIO DA SAÚDE. Dengue diagnóstico e manejo clínico adulto e criança. 5. ed. Brasília: MS, 2016. 7 p. ISBN: 978-85-334-2344-2.

NG, Deborah HL et al. The Significance of Prolonged and Saddleback Fever in Hospitalised Adult Dengue. PLoS One, [s. I.], v. 11, n. 12, p. e0167025, 9 Dec. 2016.

PADYANA, Mahesha et al. Clinical Profile and Outcome of Dengue Fever in Multidisciplinary Intensive Care Unit of a Tertiary Level Hospital in India. Indian J Crit Care Med, [s. I.], v. 23, n. 6, p. 270-273, June. 2019.

RAO, Pooja et al. Correlation of Clinical Severity and Laboratory Parameters with Various Serotypes in Dengue Virus: A Hospital-Based Study. Int J Microbiol, [s. I.], v. 2020, 15 Dec. 2020.

SALLES, Tiago Souza et al. History, epidemiology and diagnostics of dengue in the American and Brazilian contexts: a review. Parasites \& Vectors, [s. I.], v. 264, n. 11, 24 Apr. 2018.

SHIVKAR, Rajni R.; PADWAL, Meghana K.; VAIDYA, Akanksha. Correlation of Liver Transaminases with Platelet count in Dengue patients from Tertiary Care Hospital in Western India. Int J Cur Res Rev, [s. I.], v. 10, n. 5, Mar. 2018. 
TEERASARNTIPAN, Tongluk et al. Acute liver failure and death predictors in patients with dengue-induced severe hepatitis. World J Gastroenterol , [s. I.], v. 26, n. 33, p. 4983-4995, 7 Sept. 2020.

WANG, Jingen et al. Epidemiological and clinical analysis of the outbreak of dengue fever in Zhangshu City, Jiangxi Province, in 2019. Eur J Clin Microbiol Infect Dis, [s. I.], v. 40, n. 1, 14 Aug. 2020.

WARDHANI, Puspa et al. Clinical and virological characteristics of dengue in Surabaya, Indonesia. PLoS One, [s. I.], v. 12, n. 6, p. 0178443, 2 June. 2017.

WHO - WORLD HEALTH ORGANIZATION. Comprehensive Guidelines for Prevention and Control of Dengue and Dengue Haemorrhagic Fever . Geneva: WHO, 2011.

WONG, Joshua G. X. et al. Identifying Adult Dengue Patients at Low Risk for Clinically Significant Bleeding. PLoS One, [s. I.], v. 11, n. 2, p. e0148579, 5 Feb. 2016.

$\mathrm{XU}$, Chuanhui et al. Differences in clinical features and dengue severity between local and migrant Chinese with dengue infection in Singapore. PLoS One, [s. I.], v. 13, n. 8, p. e0201441, 15 Aug. 2018.

ZHAO, Lingzhai et al. Slow resolution of inflammation in severe adult dengue patients. BMC Infect Dis , [s. I.], v. 10, 14 June. 2016.

Enviado: Agosto, 2021.

Aprovado: Dezembro, 2021. 